\title{
PENDAMPINGAN GERAKAN LITERASI SEKOLAH DALAM PEMBELAJARAN DI SEKOLAH DASAR
}

\author{
Nisfil Maghfiroh Meita ${ }^{1}$, Herowati $^{2}$ \\ ${ }^{1,2)}$ Dosen Fakultas Keguruan dan Ilmu Pendidikan Universitas Wiraraja \\ Email: ${ }^{1)}$ nisfil@wiraraja.ac.id, ${ }^{2}$ herowati.fkip@wiraraja.ac.id
}

\begin{abstract}
ABSTRAK
Buku merupakan jendela dunia, dengan membaca buku akan memberikan wawasan yang luas. Kebiasaan untuk membaca buku menjadi pondasi peserta didik untuk selalu belajar dan membuka wawasan baru. Saat ini membaca buku menjadi sangat mahal dari pada menggunakan gawai. Selain itu sulitnya akses buku bacaan yang tidak tersedia di lembaga pendidikan khususnya di SD Darmista 1 Kecamatan Lenteng Kabupaten Sumenep. Sarana perpustakan belum tersedia, sehingga peserta didik tidak memiliki kesempatan untuk berwisata literasi di sekolah. Gerakan literasi sekolah (GLS) tidak harus membeli buku dan tidak harus selalu membaca buku pelajaran, salah satu kegiatan di dalam gerakan literasi adalah "kegiatan 15 menit membaca buku non-pelajaran sebelum waktu belajar dimulai”. Hal ini dilakukan bertujuan untuk membiasakan peserta didik untuk membaca buku minimal 1 kali dalam 1 hari meskipun hanya sebentar. Sesuai dengan pepatah yang mengatakan "sedikit demi sedikit, lama-lama menjadi bukit" artinya usaha/ upaya kecil yang terusmenerus pasti akhirnya akan memberikan hasil. GLS diharapkan dapat menumbuhkan minat baca dan menstimulus keterampilan baca peserta didik. Materi baca berisi nilai-nilai budi pekerti, berupa kearifan lokal, nasional, dan global yang disampaikan sesuai tahap perkembangan peserta didik. Membiasakan peserta didik untuk membaca buku harus disertai kerjasama seluruh warga sekolah dan masyarakat. Usia 7-12 merupakan usia peserta didik di sekolah dasar (SD), jika di usia ini peserta didik sudah terbiasa menyempatkan waktu untuk membaca buku maka di jenjang pendidikan menengah sampai dengan perguruan tinggi juga akan menjadi kebiasaan.
\end{abstract}

Kata kunci: GLS, Sekolah Dasar

\section{PENDAHULUAN}

Studi yang dilakukan Central Connecticut State University pada tahun 2016 mengenai "Most Literate Nations in The World" menyebutkan bahwa Indonesia menempati urutan ke-60 dari total 61 negara, atau dengan kata lain minat baca masyarakat Indonesia disebut-sebut hanya sebesar 0,01 persen atau satu berbanding sepuluh ribu (Rossa dan Nodia, 2018). Minat baca berkurang disebabkan oleh beberapa situasi dan kondisi, salah satunya adalah sulitnya akses buku bacaan yang tidak tersedia di lembaga pendidikan khususnya di SD Darmista 1 Kecamatan Lenteng Kabupaten Sumenep. Sarana perpustakan belum tersedia, sehingga peserta didik tidak memiliki kesempatan untuk berwisata literasi di sekolah.

Membiasakan peserta didik untuk membaca buku harus disertai kerjasama dari seluruh warga sekolah (guru, peserta didik, orang tua/wali murid) dan masyarakat, atau ekosistem pendidikan. Penyebab lain kurangnya minat peserta didik untuk membaca adalah kurangnya pengondisian dan pemberian motivasi dari guru agar peserta didik rajin membaca buku, sehingga peserta didik kurang termotivasi untuk membaca. Rendahnya minat baca di Indonesia, menurut Colin McElwee, Co-Founder Worldreader, salah satunya dipengaruhi oleh sulitnya akses terhadap buku. Tak hanya itu, Colin juga mengatakan bahwa gempuran inovasi di bidang teknologi membuat masyarakat 
terutama generasi milenial lebih senang menatap layar gawai dibandingkan membaca buku (Rossa dan Nodia, 2018). Usia 7-12 merupakan usia peserta didik di sekolah dasar (SD), jika di usia ini peserta didik sudah terbiasa menyempatkan waktu untuk membaca buku maka di jenjang pendidikan menengah sampai dengan perguruan tinggi juga akan menjadi kebiasaan. Sekolah dasar merupakan jenjang pendidikan terlama dari pada jenjang pendidikan lainnya oleh sebab itu gerakan literasi sekolah sangat disarankan dilakukan di sekolah dasar.

\section{METODE}

Pelaksanaan pengambdian kepada masyarakat di SDN Darmista 1 terdiri dari 4 tahapan yaitu: 1) Persiapan; 2) Sosialisasi; 3) Pelaksanaan; dan 4) Pendampingan dan Evaluasi. GLS menciptakan ekosistem pendidikan di SD yang literat. Ekosistem pendidikan yang literat (Huhammad, 2016) adalah lingkungan yang: 1) ramah dan menyenangkan untuk peserta didik, sehingga lebih semangat dalam belajar; 2) menunjukkan rasa menghargai sesama, peduli, dan empati; 3) meningkatkan rasa ingin tahu dan cinta pengetahuan; 4) mengembangkan kemampuan berkomunikasi; dan 5) mengakomodasi partisipasi lingkungan eksternal SD dengan seluruh warga sekolah.

GLS dapat memperkuat budi pekerti sesuai dalam Peraturan Menteri Pendidikan dan Kebudayaan Nomor 23 Tahun 2015. Salah satu kegiatan di GLS adalah "kegiatan 15 menit membaca buku nonpelajaran sebelum waktu belajar dimulai". GLS dapat dilakukan dengan tiga tahapan seperti pada gambar 1 .

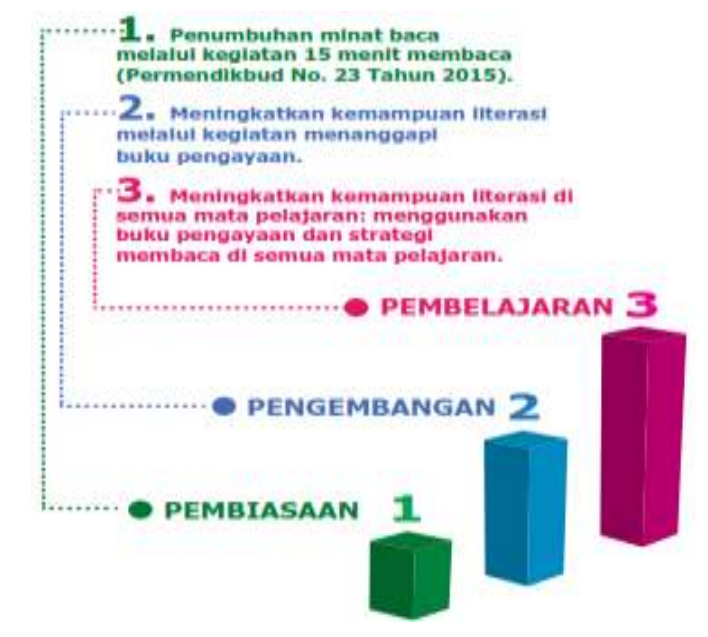

Gambar 1. Tahapan Gerakan Literasi Sekolah

Target dalam pengabdian kepada masyarakan di SD Darmista 1 adalah pada tahapan pembiasan, karena kebiasaan tidak dapat berubah dalam waktu singkat. Peserta didik akan di dampingi untuk menambah minat membaca buku sehingga menjadi sebuah kebiasaan yang rutin. Jika pada tahapan pembiasaan berhasil maka dapat dilanjutkan ke tahap pengembangan dan dan pembelajaran. Pada tahap pembiasan agenda kegiatan GLS yang perlu diperhatikan (Huhammad, 2016) adalah: “1) kecakapan literasi yang ditumbuhkan; 2) fokus dan prinsip kegiatan; 3) prinsip-prinsip kegiatan membaca; dan 4) kegiatan membaca dan penataan lingkungan kaya literasi.

Pelaksanaan pendampingan gerakan literasi sekolah dalam pembelajaran di Sekolah Dasar Negeri Daramista 1 yaitu: a) Membaca 15 menit sebelum pelajaran dimulai. Buku yang dibaca adalah buku nonpelajaran, Buku non pelajaran yang dimaksudkan di sini bisa berupa buku cerita, novel ataupun buku jenis lain yang lebih mengajarkan nilai budi pekerti, kearifan lokal, nasionalisme dan lain-lain yang lebih disesuaikan pada tahap perkembangan peserta didik; b) Menata sarana dan lingkungan kaya literasi; c) Menciptakan lingkungan kaya teks; 
d) Memilih buku bacaan di SD; dan e) Pelibatan publik.

\section{HASIL DAN PEMBAHASAN}

Kepala sekolah SDN Darmista 1 adalah H. Mulhaji, S.Pd, M.Pd. SDN Darmista 1 terdiri dari 6 kelas, rincian masing-masing nama wali kelas dari kelas 1 s/d 6 adalah sebagai berikut:

a. Guru Kelas 1: Hannawati, S.Pd.SD

b. Guru Kelas 2: Kiptiyah, S.Pd.SD

c. Guru Kelas 3: Sadik, A.Ma.Pd

d. Guru Kelas 4: Yumatina, S.Pd.SD

e. Guru Kelas 5: Nurul Hozeima, S.Pd

f. Guru Kelas 6: Moh. Ra'is, S.Pd.SD

Deskripsi rencana jadwal kegiatan pengabdian kepada masyarakat di SDN Darmista 1 terdapat pada tabel 1.

Tabel 1. Kegiatan Pengabdaian Kepada Masyarakat di SDN Darmista 1

\begin{tabular}{|c|c|c|}
\hline $\mathrm{No}_{0}$ & Ienis Kegititan & Walitu \\
\hline 1 & Pasingan & O1 Naret 2019 sd 30 Mard 2019 \\
\hline 2 & Sosializsi & 01 Apl 2019 sd 30 Apqu12019 \\
\hline 3 & Pelakenom & O1 Mei 2019 sd 31 Mei 2019 \\
\hline 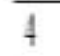 & Pradarginenn dan Eraluasi & (2) Juxi 2019 sd 30 Agrsts 2019 \\
\hline
\end{tabular}

\section{Persiapan GLS di SDN Darmista 1}

Tahapan persiapan dilakukan hari Senin pada tanggal 25 Maret 2019 dengan agenda menginformasikan tahapan kegiatan pengadian kepada masyarakat kepada kepala sekolah, penyerahan buku panduan GLS, menyiapkan buku bacaan, serta merencakan waktu sosialisasi dan pelaksanaan GLS.

\section{Sosialisasi GLS di SDN Darmista 1}

Tahapan sosialisasi dilakukan hari Senin pada tanggal 1 April 2019 dengan agenda kegiatan menata sarana dan lingkungan baca atau sudut baca di masing-masing kelas; dan sosialisasi penentuan pelaksanaan GLS pada hari selasa dan kamis 15 menit sebelum pembelajaran dimulai. Tahapan ini dilakukan sebelum UAS, Ujian Praktek, dan Ujian Nasional Kelas 6 dilaksanakan.

\section{Pelaksanaan GLS di SDN Darmista 1}

Pelaksanaan GLS berlangsung selama lima kali, yaitu: 1) hari selasa tanggal 2 Mei 2019; 2) hari kamis tanggal 9 Mei 2019; 3) hari selasa tanggal 14 Mei 2019; 4) hari kamis tanggal 16 Mei 2019; dan 5) hari selasa tanggal 28 Mei 2019. Pelaksanaan GLS melibatkan seluruh guru, peserta didik, kepala sekolah, tim dosen pengabdian kepada masyarakat, dan mahapeserta didik.

Pelaksanaan GLS seharusnya bisa selesai di pertengan bulan Mei 2019 di minggu ke tiga. GLS harus diperpanjang karena bebera faktor yaitu: 1) libur puasa pada tanggal 4-7 Mei 2019; 2) Ujian Kenaikan Kelas (UKK) bagi peserta didik KTSP pada tanggal 18-23 Mei 2019; dan 3) Ujian Kenaikan Kelas (UKK) bagi peserta didik K13 pada tanggal 18-25 Mei 2019.

Pendampingan gerakan literasi sekolah dalam pembelajaran di Sekolah Dasar Negeri Daramista 1 menghasilkan budaya membaca 15 menit sebelum pelajaran dimulai setiap hari selasa dan kamis, sedangkan hari-hari lainnya digunakan untuk mengembangkan karakter lainnya seperti religius dan nasionalis. Gerakan litersasi sekolah dilakukan dua kali tiap minggu, membaca buku literasi dapat dilakukan di dalam ruang kelas atau di luar kelas (gambar 2 dan 3). Literasi yang dibaca adalah buku non-pelajaran (gambar 4). 


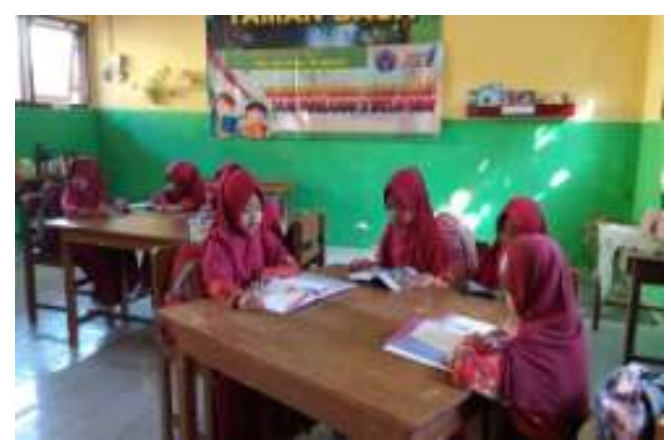

Gambar 2. Kegiatan Gerakan Literasi Sekolah di Dalam Ruangan

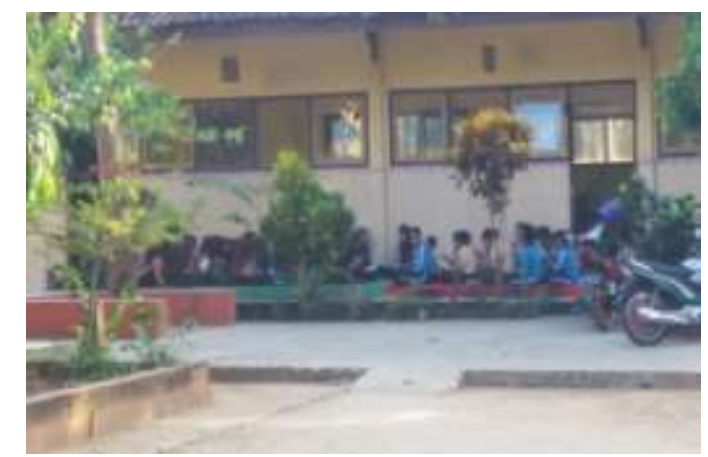

Gambar 3. Kegiatan Gerakan Literasi Sekolah di Luar Ruangan

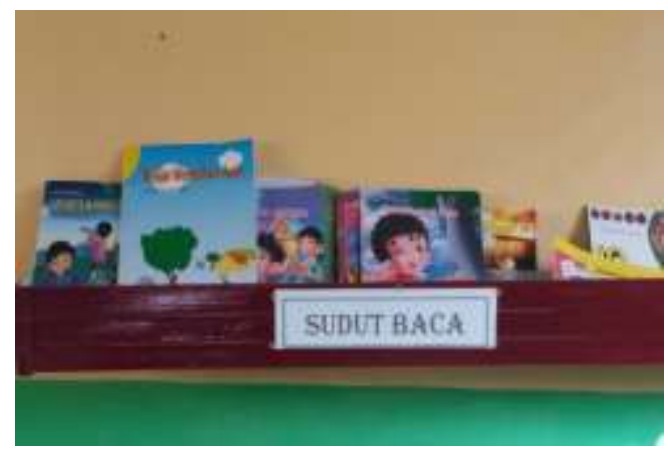

Gambar 4. Sudut Baca dan Literasi NonPelajaran

\section{Pendampingan dan Evaluasi GLS di SDN}

Darmista 1

Pendampingan dilakukan setelah dua minggu pelaksanaan GLS berakhir untuk memperhatikan kemandirian mitra dalam pelaksanaan GLS. Pendampingan terjadi pada hari selasa tanggal 11 Juni 2019. Pelaksanaan evaluasi juga diberikan waktu selama dua minggu yaitu pada hari kamis tanggal 20 Juni 2019. Pada tahapan ini pihak sekolah diinformasikan agar tetap konsisten dalam pelaksanaan GLS, tetap menjaga kebersihan dan kenyamanan sudut baca bagi peserta didik sehingga minat baca peserta didik tetap konsisten, mengusahakan sumber bacaan tidak monoton, konsisten dalam menukar buku bacaan secara periodik, menambah koleksi bacaan baik dari hasil swadaya atau hibah.

\section{Pembahasan}

\section{Persiapan GLS di SDN Darmista 1}

Persiapan yang dilakukan yaitu 1) memberitahukan pihak sekolah terkait dengan pelaksanaan pengabdian kepada masyarakat tentang GLS; 2) memberikan buku panduan gerakan literasi sekolah di sekolah dasar terbitan Direktorat Jenderal Pendidikan Dasar dan Menengah Kementerian Pendidikan dan Kebudayaan tahun 2016 dalam bentuk hard file dan soft file; 3) menyiapkan buku bacaan non-pelajaran sesuai dengan tahap perkembangan peserta didik seperti buku dongeng, cerita-cerita nabi, buku bacaan bergambar, dan lain-lain; dan 5) mendiskusikan hari/ waktu pelaksanaan sosialisasi dan kegiatan GLS.

\section{Sosialisasi GLS di SDN Darmista 1}

Sosialisasi dilakukan pada guru-guru, kepala sekolah, dan peserta didik di SDN Darmista 1 sehingga GLS mendapatkan dukungan dari seluruh masyarakat SDN Darmista 1. Menata sarana dan lingkungan baca atau sudut baca di masing-masing kelas juga dilakukan pada saat sosialisasi. Kesimpulan dari sosialisasi yang dilakukan adalah 15 menit membaca buku non-pelajaran sebelum pembelajaran dimulai, menetapkan hari GLS jatuh pada hari selasa dan kamis, karena senin ada kegiatan upacara bendera, rabu kegiatan olahraga bersama, dan jum'at adalah hari mengaji bersama. 
Pelaksanaan GLS di SDN Darmista 1

Kecakapan literasi yang ditumbuhkan pada tahap pembiasaan GLS di antaranya adalah peduli, menghargai, menumbuhkan semangat ingin tahu dan cinta pengetahuan, serta komunikasi yang lancar. Fokus dan prinsip kegiatan di tahap pembiasaan GLS yaitu menumbuhkan dan mengembangkan karakter gemar membaca, lingkungan kelas yang kaya literasi sehingga mempermudah peserta didik untuk mendapatkan literasi dan memberikan kebebasan pada peserta didik untuk memilih literasi yang disukai oleh peserta didik.

Prinsip-prinsip kegiatan membaca di tahap pembiasaan GLS adalah membaca selama 15 menit sebelum pembelajaran dimulai, membaca buku non-pelajaran sehingga membaca lebih menyenangkan. Jika peserta didik sudah terbiasa senang membaca harapannya adalah meningkatnya minat baca masyarakat Indonesia sehingga persentase minat baca bisa lebih besar dari $0,01 \%$. Kegiatan membaca dan penataan lingkungan kaya literasi di tahap pembiasaan GLS adalah memunculkan sudut baca di setiap ruang kelas sehingga literasi lebih dekat dengan peserta didik, menata dan mengatur sudut baca agar selalu rapi, menarik, dan menyenagkan sehingga peserta didik tidak bosan atau senang pada saat bembaca buku.

Pendampingan dan Evaluasi GLS di SDN Darmista 1

Hasil pendampingan dan evaluasi setelah pelaksanaan GLS di SDN Darmista 1 menunjukkan bahwa sekolah mitra pengabdian kepada masyarakat tetap rutin melakukan GLS dan buku bacaan nonpelajaran secara periodik dua bulan sekali di tukar dengan kelas-kelas lain secara bergantian, sehingga sumber literasi peserta didik tidak monoton.

Kendala yang muncul dalam kegiatan pengabdian kepada masyarakat di SDN Darmista 1, diantaranya adalah 1) Ruang perpustakaan yang tidak dapat digunakan sesuai dengan fungsinya karena bangunan perpustakaan sekolah sudah sangat tua dan rapuh sehingga dengan alasan takut membahayakan peserta didik maka gedung perpustakaan kosong; 2) Tim pengabdian kepada masyarakat masih kurang dalam hal menambah jumlah koleksi buku yang lebih banyak dan lebih beragam; dan 3) jadwal pelaksanaan kegiatan pengadian kepada masyarakat di SDN Darmista 1 terbentur dengan kegiatan sekolah dan libur puasa, sehingga pelaksaan perlu diperpanjang sampai pelaksanaan GLS selesai.

Faktor pendukung dalam kegiatan pengabdian kepada masyarakat di SDN Darmista 1 yaitu: 1) adanya komunikasi yang baik dan terbuka antar sesama tim, baik dosen dan mahapeserta didik, dan pihak sekolah. Hal ini menyebabkan setiap permasalahan yang ada dapat dicarikan solusinya dengan cepat dan tepat; 2) Pihak sekolah memberi kebebasan untuk keluar masuk sekolah kepada tim untuk mendapatkan kebutuhan pencapaian program maupun menghadiri proses perkuliahan; dan 3) Tanggapan yang antusias dari peserta didik pada saat pelaksanaan kegiatan pengabdian kepada masyarakat di SDN Darmista 1.

\section{SIMPULAN}

Pendampingan gerakan literasi sekolah dalam pembelajaran di Sekolah Dasar Negeri Darmista 1 setiap hari selasa dan kamis, dengan membiasakan peserta didik untuk membaca buku non-pelajaran 15 menit sebelum pelajaran dimulai dapat 
menumbuhkan dan mengembangkan karakter gemar membaca, lingkungan kelas yang kaya literasi sehingga mempermudah peserta didik untuk mendapatkan literasi dan memberikan kebebasan pada peserta didik untuk memilih literasi yang disukai oleh peserta didik.

\section{DAFTAR PUSTAKA}

Muhammad, Hamid. (2016). Panduan Gerakan Literasi Sekolah di Sekolah Dasar. Jakarta: Direktorat Jenderal Pendidikan Dasar dan Menengah Kementerian Pendidikan dan Kebudayaan.

Permendikbud. (2015). Peraturan Menteri Pendidikan dan Kebudayaan.

Rossa, Vania dan Nodia, Firsta. 21 Februari, (2018). Miris, Minat Baca Masyarakat Indonesia Hanya 0,01 Persen. Suara.com 